\title{
Spatio-temporal patterns of larval fish ingress to Chincoteague Bay, Maryland, USA during winter and spring 2004 to 2007
}

\author{
Joseph W. Love ${ }^{1, *}$, Daniel F. Luers ${ }^{1}$, Branson D. Williams ${ }^{1,2}$ \\ ${ }^{1}$ University of Maryland Eastern Shore, NOAA Living Marine Resources Cooperative Science Center, \\ Department of Natural Sciences, Princess Anne, Maryland 21853, USA \\ ${ }^{2}$ Present address: College of William and Mary, Virginia Institute of Marine Science, PO Box 1346, Gloucester Point, \\ Virginia 23062, USA
}

\begin{abstract}
We documented larval fish ingress to Chincoteague Bay (Maryland, USA) for 3 field seasons (December 2004 to April 2005, November 2005 to April 2006, November 2006 to April 2007) to evaluate spatial and temporal differences in ichthyoplankton catches. Larval fish assemblages were represented by 11 species. The most abundant larvae included American eel Anguilla rostrata, summer flounder Paralichthys dentatus, and spot Leiostomus xanthurus. Common larval fishes did not differ in number between northern and southern inlets that provide access between Chincoteague Bay and the Atlantic Ocean, but did differ among years and between seasons. Wind angle and offshore water temperature were predictive of ingress for some species, but patterns were not strong. Canonical correspondence analyses of ichthyoplankton assemblage data indicated that ingress was better predicted by season and year rather than specific environmental variables (e.g. offshore water temperature, moon phase, wind angle). Seasonal patterns in larval fish ingress were consistent with those from other coastal lagoon networks along the eastern USA seaboard. Preliminary work suggests that interannual variation in larval fish abundance was generally related to juvenile fish abundance. We encourage more efforts aimed at larval fish monitoring, which may serve as a relatively inexpensive method for addressing larger spatio-temporal scale questions about fish recruitment.
\end{abstract}

KEY WORDS: Environment $\cdot$ Coastal bay $\cdot$ Inlet $\cdot$ Recruitment $\cdot$ Marine $\cdot$ Estuary

\section{INTRODUCTION}

The larval life stage of marine fishes is highly susceptible to mortality. After dispersing long distances across the continental shelf, larval fishes enter inlets and estuaries that provide nutrients and refugia (e.g. seagrasses) from predators, but may also expose them to environmental stressors (e.g. contaminants). Larval fishes constitute an important prey base for consumers in estuaries or, if they survive their first year of life, they may recruit into economically valuable fisheries and sustain spawning populations.

Composition and densities of ichthyoplankton are affected by season and meteorological or hydrographic variation (Hettler \& Hare 1998, Brown et al. 2000, 2004). Recruitment and distribution of fish larvae are influenced by climatic phenomena such as El Niño/La Niña events (Sánchez-Velasco et al. 2004). Seasonal differences in ichthyoplankton composition are predictable (Warlen et al. 2002), with intraseasonal variation that may be attributed to environmental factors such as wind direction or tidal flow. However, relationships between environmental variability and ichthyoplankton densities have not been well-documented for many species. Here, we report interannual and seasonal patterns of larval fish recruitment to a mid-Atlantic coastal lagoon (USA), and show whether variation in ingress is attributable to selected environmental factors. 


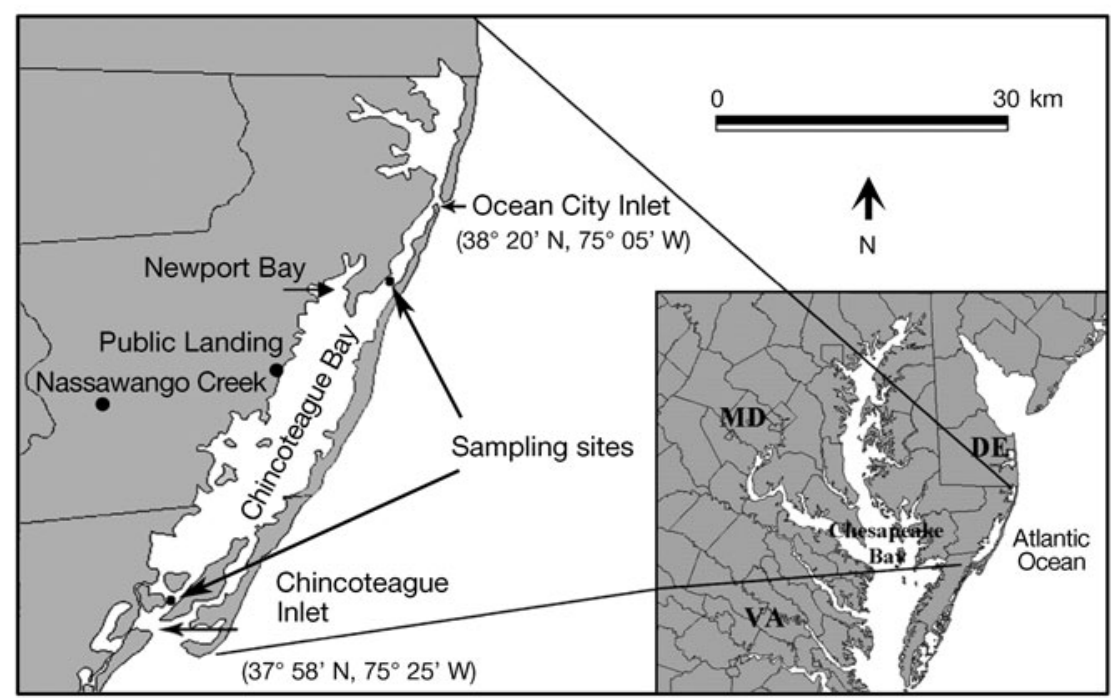

Fig. 1. Chincoteague Bay, with reference to Ocean City Inlet (Maryland) and Chincoteague Inlet (Virginia), and the Delaware-Maryland-Virginia Peninsula (inset)

Along the eastern shore of Maryland and Virginia a number of fishes use estuaries as nurseries (Casey \& Wesche 2001), including species that are recreationally valuable (e.g. summer flounder Paralichthys dentatus L.), commercially valuable (e.g. Atlantic menhaden Brevoortia tyrannus (Latrobe)), and ecologically valuable (e.g. Bay anchovy Anchoa mitchilli (Cuvier \& Valenciennes)). Despite their potential value as nurseries for Atlantic coastal stocks, no work has been published on the use of the coastal lagoons of Maryland and Virginia (hereafter, the coastal lagoons) by larval fishes. Larval fish studies of the coastal lagoons also fill an important geographic data gap between more northerly and southerly inlets with the longest running larval fish monitoring programs on the eastern coast of the USA (Little Egg Inlet, New Jersey and Beaufort Inlet, North Carolina) (Hettler \& Hare 1998, Warlen et al. 2002).

The objectives of our study were (1) to determine the abundance and species of larval fish entering the largest coastal estuary of Maryland and Virginia, Chincoteague Bay, (2) to determine if larval fish densities differ between seasons (November to January; February to April), among years (2004 to 2007), or between 2 inlets of Chincoteague Bay, (3) to determine if measured climatic and habitat variables were significantly related to composition of ichthyoplankton entering Chincoteague Bay, and (4) to provide preliminary results on how larval densities and environmental conditions affected juvenile abundance in 3 years for 3 species of fish: Atlantic croaker Micropogonias undulatus (L.), spot Leiostomus xanthurus Lacepède, and summer flounder Paralichthys dentatus.

\section{MATERIALS AND METHODS}

Study area. The coastal bay watershed of Maryland and Virginia provides habitats for over 100 species of estuarine or marine fish (Schwartz 1964, Casey \& Wesche 2001). The watershed is comprised of 5 lagoons, of which Chincoteague Bay is the largest (Fig. 1). Chincoteague Bay is connected to the Atlantic Ocean via 2 major inlets: Ocean City Inlet (OCI: to the north) and Chincoteague Inlet (CI: to the south). CI is much larger and geologically more stable, while OCI was created by a hurricane in the early 20th century, and is much smaller. The importance of the recently created OCI as a dispersal corridor for fishes has never been established. Chincoteague Bay is shallow (average depth $=1.2 \mathrm{~m}$, Wazniak et al. 2005), tidally influenced (0.3 to $0.4 \mathrm{~m}$ tidal height) from both inlets, and is relatively unimpacted by humans (Carruthers et al. 2005).

Fish collection. Larval fishes were collected from December to April (2004 to 2005), November to April (2005 to 2006 and 2006 to 2007) during 2 seasons: November to February, winter; March to April, spring. During 2004- 2005, samples were collected biweekly from both OCI and CI. During the remaining years, samples were collected weekly from OCI. We did not survey CI for additional years because of logistic and funding constraints. Ichthyoplankton were sampled using bridled plankton nets $(1 \mathrm{~m}$ diameter, $1 \mathrm{~mm}$ mesh) deployed from a man-made structure surrounded by water (e.g. a pier). A float was attached to the top of the net. Nets fished in water that was $1 \mathrm{~m}$ to $2 \mathrm{~m}$ deep, for approximately $90 \mathrm{~min}$, beginning near the mid-flood tide and ending at high tide. All sampling was conducted at night, when passage of larval fish through the inlets is greater (Schaffler et al. 2009). Samples were preserved using a buffered $10 \%$ solution of formalin. In the laboratory, fishes were identified to species using Fahay (1983), Murdy et al. (1997), and Able \& Fahay (1998). Catch per unit effort (CPUE) was computed for each species as fish caught $\mathrm{h}^{-1}$. Larval species' CPUEs were square-root transformed to help normalize variances prior to analyses.

Environmental variables. Flow and volume of water filtered by the net was measured using a General Oceanics Environmental flow meter. Volume $\left(\mathrm{m}^{3}\right)$ was calculated based on dimensions of the net and flow of water through the net:

$$
0.785 \times[(C \times \mathrm{K}) / 999999]
$$


where $C$ is the difference in initial and final count on the flow meter and $\mathrm{K}$ is a rotor constant equal to 26873. Flow rate $\left(\mathrm{cm} \mathrm{s}^{-1}\right)$ was calculated as:

$$
\{[(\mathrm{C} \times \mathrm{K}) / 999999] \times 100\} / t
$$

where $t$ is the time the net was deployed in seconds. Because flow rates were occasionally too low to be accurately measured by our flow meter, we categorized flow rate as either high or low using a frequency distribution of flow speed: 61 low flow events $(<3 \mathrm{~cm}$ $\mathrm{s}^{-1}$ ) and 23 high flow events $\left(>3 \mathrm{~cm} \mathrm{~s}^{-1}\right)$. This categorization was used as a dummy effect in subsequent analyses (0: low flow rate, 1: high flow rate).

Climatic variables were recorded from online sources: lunar phase (\% fullness, available at: www. saltwatertides.com), offshore water temperature $\left({ }^{\circ} \mathrm{C}\right)$ (www.ndbc.noaa.gov/maps/Chesapeake_Bay.shtml for Buoy 44009 approximately $64 \mathrm{~km}$ northeastward from OCI), and wind direction (bearing in degrees: ${ }^{\circ}$; usairnet. com, enter zipcode 21842). Wind direction was measured at Ocean City Airport (Ocean City, Maryland). Water temperature $\left({ }^{\circ} \mathrm{C}\right)$ and salinity (ppt) at the site were recorded prior to sampling using a hand-held YSI-85 (Yellow-Springs Instruments).

Statistical analyses. Seasonal and spatial effects: We determined if larval fish assemblages differed among years of sampling, between seasons, or between sites during the first year (CI vs. OCI). Three different nonparametric, multi-response permutation procedures (MRPP) were used to determine if larval fish assemblages differed by year, season, or site. This analysis ranks species based on their abundance in the data set and is appropriate for community data, which usually violate assumptions of multivariate normality necessary for parametric tests such as discriminant analysis or multivariate analysis of variance (McCune \& Grace 2002). To compare assemblage dissimilarity among seasons, years, and sites, we used a Sörensen, Bray-Curtis distance measure. Distances among sampling units within each $a$ priori defined group were computed and represented by delta $(\delta)$. Smaller $\delta$ indicates more similarity among sample units within each group. The probability of achieving a smaller $\delta$ by chance was calculated by a test statistic (T), which is the difference of the observed $\delta$ and expected $\delta$, divided by the square root of variance in $\delta$. The expected $\delta$ was determined from a distribution of data generated from a permutation procedure yielding all possible $\delta$ values. Highly negative T-values indicated greater difference between observed and expected $\delta$ (McCune \& Grace 2002). The strength of dissimilarity, which is independent of sample size, was quantified by a statistic (A) that is the chance-corrected within group agreement statistic (McCune \& Grace 2002). The A statistic is calculated as:

$$
1 \text { - observed } \delta \text { /expected } \delta
$$

and describes within-group homogeneity of variance (i.e. similarity among site-specific assemblages within each group) compared to that expected for random assignment of sites to groups. When all sites within groups are identical to one another, $\mathrm{A}=1$; when heterogeneity within a group equals that expected by chance, $\mathrm{A}=0$. Usually, $\mathrm{A}<0.10$ in community ecology, and a large effect is needed to obtain statistical significance when sample size is small (McCune \& Grace 2002).

Environmental effects: To initially explore the relationship between environmental factors and ichthyoplankton CPUE, a Spearman's rank correlation ( $\rho$ ) analysis was performed on the data. Spearman's $\rho$ was used to determine the level of correlation between variation in larval fish CPUE and variation in environmental variables. This non-parametric analysis is similar to a Pearson's correlation analysis, but for ranked and ordered values.

We also used a direct gradient analysis, canonical correspondence analysis (CCA, ter Braak 1986), to determine if variation in the measured environmental factors was related to variation in ichthyoplankton assemblages across sampling events. The CCA analysis is a multivariate (or multiple dependent variable), multiple regression analysis that uses multiple linear regression to relate species abundances within a dataset (i.e. a site $\times$ species data matrix) to a second dataset comprised of environmental variables (i.e. a site $\times$ environmental data matrix) (Rakocinski et al. 1996, Love \& May 2006). In short, the analysis predicts the optimum abundance of each species for the environmental variables used. Theoretical species abundances were optimized because we wanted to provide a direct interpretation of species abundance in relation to environmental variables. For each species, the optimal abundance along the environmental gradient was represented by a canonical score (see below). The CCA uses multiple regression to determine if these scores for all species are related to the environmental variables. Two major assumptions of CCA are that (1) the measured environmental variables are the most important for structuring assemblages, and all other variance is ignored; and (2) there is a unimodal species response to environmental gradients. The measured environmental variables included water flow and climatic variables that would be most responsible for ichthyoplankton ingress patterns. Because of the duration of the study (winter to late spring), and the putative unimodal peaking of ingress across time (Able \& Fahay 1998), species were expected to have unimodal responses to environmental variables.

The CCA generated canonical, species scores $\left(u_{\mathrm{j}}\right)$ for an axis by weighted averaging of arbitrarily assigned site scores $\left(x_{i}\right)$ using the equation: 


$$
u_{\mathrm{j}}=\lambda^{-\alpha} \Sigma y_{\mathrm{ij}} \times x_{\mathrm{i}} / y_{+\mathrm{j}}
$$

where $\lambda^{-\alpha}$ is a scaling parameter, $y=$ species abundance, and $y_{+j}$ is the species total (ter Braak 1986, McCune \& Grace 2002). New site scores for the axis were then calculated by weighted averaging of species scores. Multiple regression was performed on new site scores (dependent variables) against predictor variables (independent variables, see below). A new set of site scores for the axis was then calculated from the multiple regression model. The scores that were calculated from weighted averaging of species scores were compared to scores fitted to the multiple regression model. In this way, scores assigned based on species distributions were compared to scores assigned based on species distributions that were constrained by environmental conditions. Through iterations of score calculation, variance between these 2 types of scores reached an absolute minimum. Site scores for each axis generated by the CCA were uncorrelated with preceding axes and standardized to a mean of 0 and a variance of 1 . Three axes were generated and interpreted from the CCA.

Three CCA models were developed and differed by predictor variables that were included in the analysis: (1) a model with only water flow and climatic predictors, (2) a model with only season and year predictors, and (3) a model with both (1) and (2). For season and year predictors, we used dummy variables that coded the first time period as 1 and the second time period as 0 . For the seasonal effect, winter (November to February) was coded as 0 and spring (March to April) was coded as 1. For the year effect, we coded 2004 to 2005 as 0 and the remaining years as $1 ; 2005$ to 2006 was coded as 0 , and the remaining years as 1. Dummy variables are commonly used in multiple regression models to include categorical effects (e.g. season or year).

In order to interpret the CCA results, we evaluated (1) interset correlations (correlations between site scores calculated from weighted averaging of species scores and environmental variables), (2) eigenvalues of each CCA axis generated from the ordination, and their significance, (3) Pearson's correlation between canonical scores and predictor variables for each canonical axis, and its significance, and (4) the CCA plot. Significance tests for eigenvalues and Pearson's correlations were performed with Monte Carlo randomization methods (1000 times). The CCA plot included species scores and arrows that represented important predictor variables from the multiple regression model.

Spearman's $\rho$ was used to determine how larval fish CPUE was related to juvenile abundances for Atlantic croaker, spot, and summer flounder, which were sampled by Maryland Department of Natural Resources. Juvenile fish abundance from Chincoteague Bay and Newport Bay were summed across sites that were consistently surveyed monthly during summer (April to October). These summed abundances were determined for each year of the ichthyoplankton survey (2005 to 2007). Fishes were collected using otter trawls and protocols described by Casey \& Doctor (2005). Juvenile abundance data from Newport Bay were included because larval fish entering Chincoteague Bay may settle in both Chincoteague Bay and Newport Bay (Fig. 1). To relate juvenile abundance to ichthyoplankton ingress for each year, we standardized the

Table 1. Eleven larval fish species collected while sampling Ocean City Inlet (OCI, Maryland, USA) and Chincoteague Inlet (CI, Virginia, USA). Data are percent ( $\%$ of the catch for the season and year) $\pm \mathrm{SD} ; \mathrm{n}$ : number of organisms caught across $\mathrm{N}$ sampling events each season (winter: November-January; spring: February-April)

\begin{tabular}{|c|c|c|c|c|c|c|c|c|}
\hline \multirow[t]{3}{*}{ Taxon } & \multirow{2}{*}{\multicolumn{2}{|c|}{$=\frac{C I}{2004-2005}$}} & \multirow{2}{*}{\multicolumn{2}{|c|}{$2004-2005$}} & \multirow{2}{*}{\multicolumn{2}{|c|}{ 2005-2006 }} & \multirow{2}{*}{\multicolumn{2}{|c|}{ 2006-2007 }} \\
\hline & & & & & & & & \\
\hline & Winter & Spring & Winter & Spring & Winter & Spring & Winter & Spring \\
\hline Ammodytes americanus & $0 \pm 0.0$ & $1 \pm 0.3$ & $0 \pm 0$ & $0 \pm 0$ & $0 \pm 0$ & $0 \pm 0$ & $0 \pm 0$ & $0 \pm 0$ \\
\hline Anchoa mitchilli & $0.2 \pm 15.6$ & $13 \pm 2.9$ & $22 \pm 1.5$ & $1 \pm 0.4$ & $4 \pm 0.5$ & $8 \pm 5.2$ & $0 \pm 0$ & $0 \pm 0$ \\
\hline Anguilla rostrata & $22 \pm 14.7$ & $74 \pm 5.6$ & $27 \pm 2.1$ & $97 \pm 37.8$ & $24 \pm 4.4$ & $47 \pm 13.0$ & $0 \pm 0$ & $29 \pm 6.4$ \\
\hline Brevoortia tyrannus & $21 \pm 11.0$ & $3 \pm 0.6$ & $5 \pm 0.3$ & $1 \pm 0.4$ & $4 \pm 0.8$ & $26 \pm 14.2$ & $0 \pm 0$ & $2 \pm 0.7$ \\
\hline Clupea harengus & $0 \pm 0$ & $7 \pm 1.0$ & $0 \pm 0$ & $0 \pm 0$ & $0 \pm 0$ & $0 \pm 0$ & $0 \pm 0$ & $0.2 \pm 0.2$ \\
\hline Conger oceanicus & $0 \pm 0$ & $0 \pm 0$ & $0 \pm 0$ & $0 \pm 0$ & $0 \pm 0$ & $0.1 \pm 0.2$ & $0 \pm 0$ & $0.6 \pm 0.2$ \\
\hline Leiostomus xanthurus & $0 \pm 0$ & $0 \pm 0$ & $0 \pm 0$ & $0 \pm 0$ & $0 \pm 0$ & $10 \pm 9.3$ & $0 \pm 0$ & $49 \pm 13.3$ \\
\hline Micropogonias undulatus & $35 \pm 24.6$ & $0 \pm 0$ & $9 \pm 0.5$ & $0.4 \pm 0.4$ & $25 \pm 2.2$ & $7 \pm 4.4$ & $100 \pm 0.5$ & $0 \pm 0$ \\
\hline Myrophis punctatus & $0 \pm 0$ & $0 \pm 0$ & $38 \pm 3.3$ & $0 \pm 0$ & $1 \pm 0.3$ & $0 \pm 0$ & $0 \pm 0$ & $0 \pm 0$ \\
\hline Ophidion marginatum & $0 \pm 0$ & $1 \pm 0.3$ & $0 \pm 0$ & $0 \pm 0$ & $0 \pm 0$ & $0 \pm 0$ & $0 \pm 0$ & $0.2 \pm 0.2$ \\
\hline \multirow[t]{2}{*}{ Paralichthys dentatus } & $0 \pm 0$ & $0 \pm 0$ & $0 \pm 0$ & $0 \pm 0$ & $42 \pm 5.1$ & $2 \pm 1.2$ & $0 \pm 0$ & $19 \pm 3.6$ \\
\hline & $\begin{array}{l}\mathrm{n}=206 \\
\mathrm{~N}=8\end{array}$ & $\begin{array}{c}\mathrm{n}=98 \\
\mathrm{~N}=10\end{array}$ & $\begin{array}{l}\mathrm{n}=21 \\
\mathrm{~N}=6\end{array}$ & $\begin{array}{l}\mathrm{n}=238 \\
\mathrm{~N}=10\end{array}$ & $\begin{array}{l}\mathrm{n}=44 \\
\mathrm{~N}=4\end{array}$ & $\begin{array}{l}\mathrm{n}=418 \\
\mathrm{~N}=11\end{array}$ & $\begin{array}{l}\mathrm{n}=1 \\
\mathrm{~N}=4\end{array}$ & $\begin{array}{l}\mathrm{n}=214 \\
\mathrm{~N}=15\end{array}$ \\
\hline
\end{tabular}


number of times that we sampled each year and season. Differences in the number of times sampled among years were standardized by randomly selecting (with replacement) 10 sampling efforts from the dataset for each season and year. For each of the 10 sampling efforts, larval species were then ranked by CPUE. The modes of the ranks for each season and year were compared to data on juvenile fish abundance. Because the transition from larval to juvenile fish may be influenced by environmental conditions, we also related juvenile abundance to: (1) offshore water temperature during the spawning season for many species collected here (January to April) (NOAA National Data Buoy Center: Buoy 44009), (2) coastal water temperature during recruitment of juveniles (March to October) (Public Landing gauge, Maryland Department of Natural Resources, Eyes on the Bay Program), and (3) average stream flow $( \pm \mathrm{SD})$ during summer (May to September) (US Geological Survey, Gauge 01485500: Nassawango Creek).

To reduce redundancy among water flow and climatic predictor variables for both Spearman's rank analysis and CCA, Pearson's correlation analysis was used to estimate correlations ( $\mathrm{r}$ ) among environmental variables; redundant variables $(r>0.60)$ were removed from analyses.

Multivariate analyses were performed with PC-ORD (Version 5.0, MjM Software). All other analyses were performed using SYSTAT (Version 11.0, SYSTAT).

\section{RESULTS}

\section{General patterns of ingress}

We collected 11 larval fish species (Table 1), and approximately 21 ind. per sampling effort during spring (February to April, 970 ind., 46 sampling efforts), and half that (12 ind. per sampling effort) in winter (November to January, 272 ind., 23 sampling efforts) (Table 1). American eel Anguilla rostrata (Lesuer) dominated assemblages during spring of most years, except 2006 to 2007 when spot was abundant. Atlantic croaker, speckled worm eel Myrophis punctatus Lütken, and bay anchovy were also commonly collected, depending on the year or inlet surveyed.

\section{Seasonal and spatial effects on ingress}

Ichthyoplankton assemblages differed among years (MRPP, $\mathrm{T}=-7.6, \mathrm{~A}=0.14, \mathrm{p}<0.0001)$ and between seasons ( $\mathrm{T}=-14.1, \mathrm{~A}=0.08, \mathrm{p}<0.0001$; Fig. 2). Variability in ichthyoplankton composition among years was explained by differences in the abundance of spot

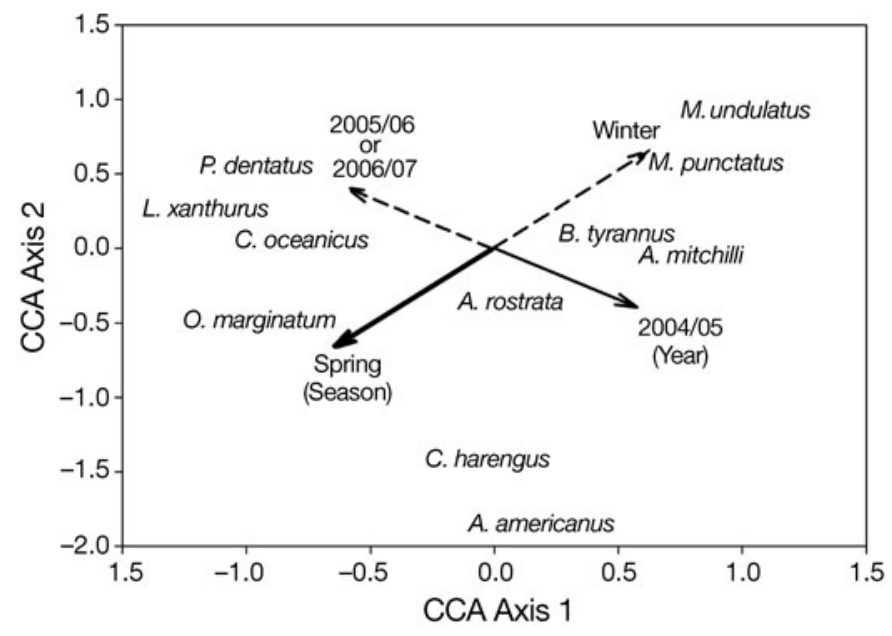

Fig. 2. Abundances from November to April of 11 larval fish species optimized for gradients of environmental and temporal variables using canonical correspondence analysis (CCA). Environmental variables were recorded from Ocean City Inlet (2004 to 2007) and Chincoteague Inlet (2004 to 2005)(Chincoteague Bay, Maryland, USA). Each point (i.e. species name) represents that species' abundance as constrained by environmental and temporal variables used here. The variables that were most related to community structure are represented by arrows in the ordination diagram. Direction and length of the arrow indicates polarity and strength of the relationship between the variable and the axis, respectively. The relative position of each species to one another, and to arrows, represents the relationship between a species' optimal abundance to other species, and to the variables. See Table 1 for full species names

and summer flounder (see Table 1). Seasonal differences in ichthyoplankton composition $(\delta=4.00)$ were stronger than interannual differences $(\delta=0.43)$. The optimal abundances for spot and conger eel were predicted to occur during spring, while optimal abundances for Atlantic croaker and speckled worm eel were predicted to occur during winter (Fig. 2). However, the seasonal composition of larval fish species differed among years. The canonical scores for summer flounder and spot were inversely correlated with the arrow for the 2004-2005 sampling year (Fig. 2), indicating that their optimal abundance was higher during the 2005-2006 and 2006-2007 sampling seasons. Because the canonical score for American eel occurred at the vertex of the arrows in the CCA plot (Fig. 2), we surmised that it was abundant relative to other species among all years and between both seasons of this survey, which is supported by CPUE data (see Table 1).

Ichthyoplankton assemblages did not differ between OCI and CI (MRPP, T $=-0.28, \delta=0.50, \mathrm{~A}=0.01, \mathrm{p}=$ 0.30). While Atlantic herring Clupea harengus L. and American sand lance Ammodytes americanus DeKay were collected only at CI, and speckled worm eel only 
at $\mathrm{OCI}$, these species were too rarely collected to result in significant differences in assemblage structure between OCI and CI (Table 1). Ingress periods and larval fish sizes were consistent with those reported for a more northernly inlet, Little Egg Inlet (New Jersey, USA; Table 2) (Able \& Fahay 1998).

\section{Environmental effects on ingress}

We determined if ichthyoplankton assemblage composition was related to environmental factors that varied over space and time (Table 3). Throughout the sampling period, average water temperature ranged from 5 to $10^{\circ} \mathrm{C}$, reflecting seasonal changes in water temperature. Flow speed was 5 times greater at CI than our sampling location near OCI. We reduced autocorrelation among predictor variables by identifying highly correlated variables using Pearson's correlation analysis. Offshore water temperature was highly correlated with site water temperature $(r=0.65)$ and wind speed $(\mathrm{r}=-0.70)$. Flow speed was highly correlated with volume of water $(r=0.87)$. Wind angle was highly correlated with precipitation $(\mathrm{r}=0.61)$. We eliminated redundant variables from subsequent analyses, and included moon fullness, offshore water temperature, flow (high vs. low), and wind angle as predictor variables in the CCA.

Of the 3 CCA models tested, the combined model had the highest eigenvalues, explaining a slightly higher level of variance in the species data $(30 \%)$ than the temporal-only $(26 \%)$ or environmental-only (12\%) models (Table 4). For the environmental-only model, wind angle was well-correlated with the axes (Table 4). The combined and temporal-only models were likely redundant, and yielded very similar eigenvalues and species-environment correlations. Eigenvalues and Pearson correlations were much lower for the environmental-only model than the temporal-only model (Table 4), suggesting that seasonal and interannual effects were better related to ingress of fish larvae than environmental variables. In addition, species' CPUEs were not well-correlated with most environmental factors ( $\rho<0.35$, for most) (Table 5).

Ingress of bay anchovy was positively correlated with warmer offshore temperature ( $\rho=0.52$; Table 5). Lower offshore water temperatures were correlated with ingress of summer flounder $(\rho=-0.40)$. Wind angle was correlated with ingress of American sand lance, Atlantic herring, and striped cuskeel Ophidion

Table 2. Six abundant larval fish species entering Chincoteague Bay of Maryland from December to April (2004-2005) and November to April (2005-2006 and 2006-2007), along with months of ingress and average size at ingress (mm). Data for Little Egg Inlet (NJ, USA; $39^{\circ} 30^{\prime} \mathrm{N}, 74^{\circ} 14^{\prime} \mathrm{W}$ ) included for comparison. SL: standard length; TL: total length

\begin{tabular}{|c|c|c|c|c|}
\hline Species & Spawning season ${ }^{\mathrm{a}}$ & Months of ingress ${ }^{\mathrm{b}}$ & $\begin{array}{l}\text { Size at ingress } \\
(\mathrm{SL} \pm \mathrm{SD})^{\mathrm{b}}\end{array}$ & $\begin{array}{l}\text { Size at ingress (TL) } \\
\text { for Little Egg Inlet }{ }^{C}\end{array}$ \\
\hline Anguilla rostrata & Jan-Jul & Dec-Apr & $54.33 \pm 4.58$ & 50-58 (Dec-Apr) \\
\hline Brevoortia tyrannus & Sep-Apr & Dec-Apr & $27.13 \pm 1.57$ & $20-110$ (Dec-Apr); 200-350 (Apr) \\
\hline Clupea harengus & Sep-Apr & Mar-Apr & $37.60 \pm 3.56$ & 30-70 (Mar-Apr) \\
\hline Leiostomus xanthurus & Nov-Feb & Mar-Apr & $12.08 \pm 2.03$ & 10-30 (Mar-Apr) \\
\hline Micropogonias undulatus & Aug-Dec & Nov-Mar & $15.07 \pm 2.50$ & 20-170 (Nov-Mar) \\
\hline Paralichthys dentatus & Sep-Dec & Dec-Mar & $13.58 \pm 2.81$ & 20 (Dec-Apr) \\
\hline
\end{tabular}

Table 3. Environmental variables measured at Ocean City Inlet (OCI; Maryland) and Chincoteague Inlet (CI; Virginia) from December to April (2004-2005) and November to April (2005-2006 and 2006-2007). Data are mean \pm SD (n)

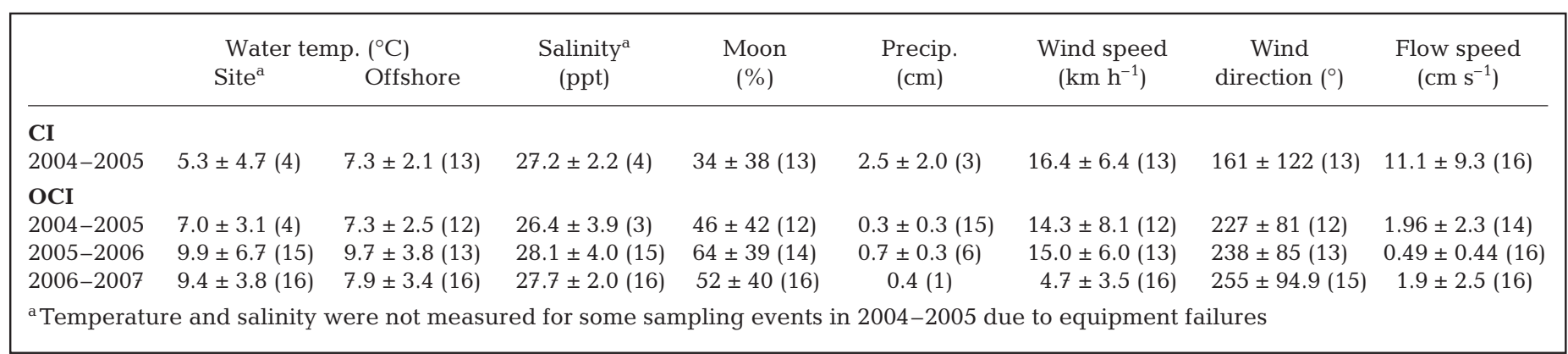


Table 4. Canonical correspondence analysis (CCA) of ichthyoplankton community data collected at Ocean City Inlet (MD, USA) and Chincoteague Inlet (VA, USA) from December to April (2004-2005), and November to April (2005-2006 and 2006-2007). Interset correlations of variables to the axis, eigenvalues, species-environmental correlations, and variance explained by each axis for 43 sampling observations can be used to interpret each axis. ${ }^{*}$ Significant $(p<0.05)$. The strength of the relationship between each species and the axis may be inferred from their final canonical scores, which are given for each species and each axis. Three CCA models were developed and included: (1) environmental and temporal predictors; (2) temporal predictors; and

(3) environmental predictors

\begin{tabular}{|c|c|c|c|c|c|c|c|c|c|}
\hline \multirow[t]{2}{*}{ Variable } & \multicolumn{3}{|c|}{ Combined model } & \multicolumn{2}{|c|}{ Temporal-only } & \multicolumn{3}{|c|}{ Environmental-only } & \multirow[b]{2}{*}{ Axis 3} \\
\hline & Axis 1 & Axis 2 & Axis 3 & Axis 1 & Axis 2 & Axis 3 & Axis 1 & Axis 2 & \\
\hline Moon fullness & -0.01 & -0.02 & -0.04 & - & - & - & -0.03 & -0.20 & -0.09 \\
\hline Offshore water temperature & 0.29 & 0.16 & -0.07 & - & - & - & 0.37 & 0.30 & -0.08 \\
\hline Flow rate & -0.24 & -0.24 & 0.38 & - & - & - & -0.38 & 0.30 & 0.16 \\
\hline Wind angle & -0.39 & 0.02 & 0.23 & - & - & - & -0.46 & 0.11 & -0.15 \\
\hline Year 2004/05 vs. other years & 0.55 & -0.31 & 0.11 & 0.57 & -0.26 & 0.18 & - & - & - \\
\hline Year $2005 / 06$ vs. other years & 0.26 & 0.06 & -0.14 & 0.26 & 0.08 & -0.24 & - & - & - \\
\hline Season (winter vs. spring) & -0.60 & -0.52 & -0.12 & -0.58 & -0.57 & -0.06 & - & - & - \\
\hline Eigenvalue & $0.47^{*}$ & $0.24^{*}$ & 0.10 & $0.45^{*}$ & $0.23^{*}$ & 0.18 & $0.22^{*}$ & 0.08 & 0.03 \\
\hline Species-Environment Corr. ${ }^{a}$ & $0.93^{*}$ & $0.80^{*}$ & 0.58 & $0.91^{*}$ & $0.76^{*}$ & 0.25 & $0.68^{*}$ & 0.54 & 0.27 \\
\hline Percent variance explained & 17.60 & 9.00 & 3.70 & 16.90 & 8.40 & 0.70 & 8.30 & 3.10 & 1.00 \\
\hline Ammodytes americanus & 0.19 & -1.85 & 1.93 & 0.45 & -1.57 & 0.67 & -1.62 & 1.04 & 0.34 \\
\hline Anchoa mitchilli & 0.75 & -0.02 & -0.05 & 0.72 & -0.01 & 0.07 & 0.49 & 0.04 & 1.00 \\
\hline Anguilla rostrata & 0.06 & -0.37 & -0.20 & 0.10 & -0.36 & -0.07 & 0.07 & -0.12 & 0.10 \\
\hline Brevoortia tyrannus & 0.46 & 0.07 & 0.13 & 0.45 & 0.11 & -0.10 & 0.17 & 0.05 & 0.02 \\
\hline Clupea harengus & -0.04 & -1.40 & 1.23 & 0.11 & -1.26 & 0.61 & -1.06 & 0.93 & 0.34 \\
\hline Leiostomus xanthurus & -1.22 & 0.25 & -0.14 & -1.27 & 0.08 & 0.07 & -0.44 & 0.13 & -0.27 \\
\hline Microponias undulatus & 1.01 & 0.94 & 0.07 & 0.86 & 0.89 & 0.11 & 0.83 & 0.26 & -0.19 \\
\hline Myrophis punctatus & 0.01 & 0.60 & 0.91 & 1.01 & 0.88 & 0.32 & -0.45 & -0.77 & -0.62 \\
\hline Ophidion marginatum & -0.89 & -0.48 & 1.31 & -0.84 & -0.39 & 0.43 & -1.29 & 1.32 & 0.47 \\
\hline Paralichthys dentatus & -0.93 & 0.57 & 0.29 & -0.87 & 0.67 & -0.01 & -0.76 & -0.38 & -0.03 \\
\hline
\end{tabular}

marginatum DeKay (Table 4). Canonical scores for these species were high for CCA axes that were also correlated with wind angle. Ingress of Atlantic herring was higher when winds were northerly $(\rho=0.72$; Table 5). These data generally suggest that ingress patterns are most strongly related to offshore water temperature and wind angle.

For 3 yr of data, larval fish CPUE, and inshore and offshore environmental factors were related to juvenile fish abundance in the coastal bays watershed of Maryland. Larval spot CPUE was not well correlated to its juvenile abundance (Table 6). However, larval Atlantic croaker and summer flounder CPUE were positively correlated with their respective juvenile abundances. In addition to larval fish CPUE, inshore environmental conditions were also correlated with juvenile fish abundance. Because of high variability in offshore water temperature, interpreting correlations between juvenile abundances of spot and Atlantic croaker to offshore water temperature is tenuous. Nevertheless, juvenile abundance of spot was higher when offshore water temperature was lower; the reverse was
Table 5. Spearman's rank correlations between catch per unit effort of larval fish species and selected environmental factors measured at Ocean City Inlet and Chincoteague Inlet from December to April (2004-2005), and November to April (2005-2006 and 2006-2007). Environmental factors include: moon fullness (Moon); offshore water temperature (Temp); flow speed (Flow); and wind angle (Angle). For each species, the number of observations used in the analysis $(\mathrm{N})$ is given. For some species not well represented in the dataset $(\mathrm{N} \leq 2)$, an analysis was not performed and was denoted as N/A

\begin{tabular}{|lccccr|}
\hline & Moon & Temp & Flow & Angle & N \\
\hline Ammodytes americanus & N/A & N/A & N/A & N/A & 1 \\
Anchoa mitchilli & 0.164 & 0.515 & -0.079 & -0.024 & 10 \\
Anguilla rostrata & -0.034 & 0.310 & 0.057 & -0.340 & 32 \\
Brevoortia tyrannus & -0.051 & 0.015 & 0.062 & -0.064 & 21 \\
Clupea harengus & -0.053 & 0.000 & -0.100 & 0.718 & 10 \\
Leiostomus xanthurus & -0.219 & 0.286 & 0.032 & 0.383 & 12 \\
Micropognias undulatus & -0.018 & 0.011 & -0.336 & -0.236 & 15 \\
Myrophis punctatus & N/A & N/A & N/A & N/A & 2 \\
Ophidion marginatum & N/A & N/A & N/A & N/A & 2 \\
Paralichthys dentatus & 0.137 & -0.401 & 0.051 & 0.060 & 19 \\
\hline
\end{tabular}

true for Atlantic croaker. Inshore conditions (i.e. stream discharge) were correlated with juvenile abundance of summer flounder. The abundance of juvenile summer flounder was higher when stream discharge during summer was lower. 
Table 6. Rank abundance (1: highest, 4: lowest) of larval and juvenile fish abundance for 3 common fish species of Chincoteague Bay, the largest of Maryland's (USA) coastal lagoons (2004-2007). Mean water temperature of Chincoteague Bay (MarchOctober), offshore water temperature, and stream discharge (Nassawango Creek, Maryland; $\mathrm{m}^{3} \mathrm{~s}^{-1}$ ) to Chincoteague Bay are also tabled $( \pm \mathrm{SD})$. Seasons are: winter (November-February); spring (March-April); and summer (May-October). NA $=$ not available. Spearman's Rank Correlation is the correlation between juvenile abundance and the environmental factor

\begin{tabular}{|c|c|c|c|c|c|c|c|}
\hline \multirow[t]{2}{*}{ Species } & \multirow[t]{2}{*}{ Year } & \multirow{2}{*}{$\begin{array}{l}\text { Larval } \\
\text { (Winter) }\end{array}$} & \multirow{2}{*}{$\begin{array}{l}\text { Larval } \\
\text { (Spring) }\end{array}$} & \multicolumn{2}{|c|}{ Temperature $\left({ }^{\circ} \mathrm{C}\right)$} & \multirow[t]{2}{*}{ Discharge } & \multirow{2}{*}{$\begin{array}{l}\text { Juvenile } \\
\text { (Summer) }\end{array}$} \\
\hline & & & & Inshore & Offshore & & \\
\hline \multirow[t]{3}{*}{ Leiostomus xanthurus } & $2004-2005$ & 4 & 4 & $20.4 \pm 7.5$ & $6.01 \pm 1.94$ & $1.42 \pm 1.23$ & 1043 \\
\hline & $2005-2006$ & 4 & 2 & $20.6 \pm 6.6$ & $7.54 \pm 1.34$ & $1.12 \pm 0.87$ & 362 \\
\hline & 2006-2007 & 4 & 1 & $21.2 \pm 6.1$ & $7.19 \pm 2.20$ & $0.13 \pm 0.14$ & 550 \\
\hline Spearman's Rank Correlation $(\rho)$ & & NA & -0.5 & -0.5 & -1.0 & 0.5 & \\
\hline \multirow{3}{*}{ Micropogonias undulatus } & $2004-2005$ & 1 & 4 & $20.4 \pm 7.5$ & $6.01 \pm 1.94$ & $1.42 \pm 1.23$ & 5 \\
\hline & $2005-2006$ & 2 & 3 & $20.6 \pm 6.6$ & $7.54 \pm 1.34$ & $1.12 \pm 0.87$ & 101 \\
\hline & $2006-2007$ & 1 & 4 & $21.2 \pm 6.1$ & $7.19 \pm 2.20$ & $0.13 \pm 0.14$ & 61 \\
\hline Spearman's Rank Correlation $(\rho)$ & & -0.9 & 0.9 & 0.5 & 1.0 & -0.5 & \\
\hline \multirow[t]{3}{*}{ Paralichthys dentatus } & $2004-2005$ & 4 & 4 & $20.4 \pm 7.5$ & $6.01 \pm 1.94$ & $1.42 \pm 1.23$ & 35 \\
\hline & $2005-2006$ & 1 & 3 & $20.6 \pm 6.6$ & $7.54 \pm 1.34$ & $1.12 \pm 0.87$ & 340 \\
\hline & $2006-2007$ & 1 & 2 & $21.2 \pm 6.1$ & $7.19 \pm 2.20$ & $0.13 \pm 0.14$ & 832 \\
\hline Spearman's Rank Correlation $(\rho)$ & & 0.9 & 1.0 & 1.0 & 0.5 & -1.0 & \\
\hline
\end{tabular}

\section{DISCUSSION}

Spatial variability in ichthyoplankton ingress was lower than seasonal and interannual patterns of ingress into coastal lagoons of Maryland. Notably, spatial patterns of ingress were investigated across a small spatial scale and a single year, which is not enough time to determine if there is an interaction between space and time on patterns of larval ingress into the coastal lagoons of Maryland. Species collected here were also collected at other inlets along the eastern USA coast (Able \& Fahay 1998). Thus far, 2 inlets of eastern North America have been monitored for larval fish ingress for $>20 \mathrm{yr}$ (Beaufort Inlet, North Carolina, USA and Little Egg Inlet, New Jersey, USA; Witting et al. 1999, Powles \& Warlen 2002). In addition to OCI, continued expansion of this project along the US northeastern coast includes ichthyoplankton monitoring in lagoons of Delaware (T. Targett pers. comm., University of Delaware) and Chesapeake Bay (E. Houde pers. comm., University of Maryland, Chesapeake Biological Laboratory). We did not find species that were not collected at other inlets. However, the degree to which ichthyoplankton communities differ across large spatial scales, such as the eastern USA coast requires further study.

Interannual differences in densities of ichthyoplankton may be due to interannual variation in movement across the continental shelf. The density of larval fishes moving across the continental shelf depends on the distribution of the spawning population, size of the spawning population, and important currents or physical oceanographic processes that carry passively drifting larvae (Quinlan et al. 1999). Annual differences in the number of fish larvae may result from differences in the size of the spawning population, which has been positively related to the level of fish recruitment (Hilborn 1997) using models from Beverton \& Holt (1957) and Ricker (1975). We did not investigate how the distribution and size of spawning populations may have explained variation in density of larval fish entering the coastal lagoons of Maryland. While our survey period did not include strong El Niño events, climatic patterns can also affect transport of larval fishes by affecting oceanic currents (Kudela \& Chavez 2000, Whitney \& Welch 2002).

Seasonal variations in larval fish ingress were consistent with those observed for other inlets, but were notably distinct (Witting et al. 1999), likely because of season-specific differences in species' reproduction. For most larval species we collected, months of ingress occurred during, or shortly after the reported spawning season for the species. Intraseasonal differences in the density of ichthyoplankton from our weekly and biweekly samples may be attributed to daily variation in the movement of fish larvae through inlets. While complex, movement of fish larvae through inlets is explained generally by tide (Boehlert \& Mundy 1988) and lunar phase (Tzeng 1985). Tidal amplitude can vary by lunar phase and wind speed or direction, and can affect current speed and salinity. Summer flounder ingress on flood tides and settle in the benthos during ebb tides (Weinstein et al. 1980). Both tide (Tzeng 1985) and chemical cues from freshwater run-off (Sorensen 1986) explain variation in ingress of American eel. Chemical cues may increase because of higher precipitation levels during El Niño events or the North Atlantic Oscillation, thereby increasing stream discharge into coastal estuaries and affecting ingress of American eel (Sullivan et al. 2006). Because a myriad 
of correlated environmental factors influences ingress patterns of larval fish, it has been traditionally difficult to isolate a single environmental cue for transport of larvae through inlets (Boehlert \& Mundy 1988).

We found a less pronounced relationship between environmental factors and ingress of larval fish than those between seasonal or annual time periods and ingress. However, some environmental factors were useful in understanding patterns of larval fish ingress to the coastal lagoons of Maryland. Winds from the north may have deflected water into the inlets, helping to direct ingress for species such as Atlantic herring and spot into Chincoteague Bay. Additionally, lower offshore water temperatures were related to ingress of summer flounder; interestingly, ingress was also highest during the 2005-2006 and 2006-2007 field seasons when offshore water temperatures were higher. Temperature variation among years may influence the distribution of the spawning stock, and warmer offshore temperatures may distribute the spawning stock closer to inlets of Maryland. Within these latter 2 sampling periods, larval summer flounder may have been most abundant during winter months during the spawning season when offshore water temperatures were lower. While we chose environmental factors commonly used in other studies of larval ingress (e.g. moon phase, precipitation), additional environmental variables may have been more useful for understanding patterns of ingress. Tidal amplitude at our site, for example, was not measured and could more directly explain the density of larval fish than its correlates, such as moon phase and wind direction. The time span for our study may not be adequate for inferring environmental relationships to ingress. While we used sampling gear consistent with other studies, our data set is represented by fewer years of study than those of other surveys illustrating environmental relationships to larval fish ingress (Witting et al. 1999, Sullivan et al. 2006). Our sampling efforts within a season may have also been too infrequent to elucidate environmental relationships to ingress. Larval fish densities may differ daily (Hettler et al. 1997), and our sampling efforts may have been too infrequent to detect a relationship between environmental conditions and peaks in larval ingress.

Our present work is insightful because (1) it is the only published account of larval fish in the coastal bays watershed, (2) seasonal ingress patterns are consistent with those from other coastal lagoon networks along the eastern USA seaboard, highlighting the possibility of meaningful, large spatial scale studies, and (3) it supports growing awareness that both density of larval fishes and estuarine conditions play important roles in juvenile fish recruitment. Many species with ichthyoplankton stages collected during this survey warrant continued monitoring because they are of practical importance to resource management in the coastal lagoons of Maryland (Casey \& Doctor 2005). Monitoring larval fish ingress may more broadly assist in determining the level of recruitment from coastal estuaries.

Using a fairly small data set for $3 \mathrm{yr}$, we found some preliminary evidence that juvenile fish abundance in coastal estuaries is related to larval fish densities, stream discharge, and water temperature. Taylor et al. (2009) showed that juvenile abundance for three coastal species was positively related to larval fish ingress using a long-time series data set. Additional years of data will undoubtedly strengthen our ability to understand such relationships for the coastal lagoons of Maryland. If spatio-temporally variable environmental factors play an important role in recruitment (Love et al. 2006), traditional estimates of spawning stock biomass may underestimate recruitment of fishes. Both water temperature and stream discharge notably influence growth and survivorship of youngof-year fishes (Rogers et al. 1984, Hare \& Able 2007, Searcy et al. 2007). Environmental conditions and warm winters influenced overwintering survivorship of juvenile Atlantic croaker more so than density of larval fish entering estuaries in the Mid-Atlantic Bight (Hare \& Able 2007). In addition to water temperature, variation in resource availability can affect recruitment (Cushing 1990) and stock-recruitment relationships (Sinclair \& Crawford 2005). Much remains to be learned about survivorship of larval to juvenile stages in coastal lagoons, and mortality rates and causes need further elucidation (Able \& Fahay 1998). We also encourage greater efforts aimed at larval fish monitoring, which may serve as a relatively inexpensive method for addressing larger spatiotemporal scale questions about fish recruitment.

Acknowledgements. We gratefully acknowledge the sampling efforts of many field volunteers who assisted with our sampling program. We also thank J. Hare, H. Walsh, J. Merriner, G. Bath-Martin and K. W. Able for help with experimental design and sampling protocol. We also thank M. Luisi for providing data on juvenile fish abundance in coastal lagoons of Maryland. This work was funded by grants to J.W.L. from NOAA Living Marine Resources Cooperative Science Center (Grant \#NA06OAR4810163).

\section{LITERATURE CITED}

Able KW, Fahay MP (1998) The first year in the life of estuarine fishes in the Middle Atlantic Bight. Rutgers University Press, Rutgers, NJ

Beverton RJH, Holt SJ (1957) On the dynamics of exploited fish populations. Fish Invest II 19:1-533

Boehlert GW, Mundy BC (1988) Roles of behavioral and physical factors in larval and juvenile fish recruitment to estuarine nurserine areas. In: Weinstein MP (ed) Larval fish and shellfish transport through inlets. American Fisheries Society, Bethesda, MD, p 51-67 
Brown CA, Jackson GA, Brooks DA (2000) Particle transport through a narrow tidal inlet due to tidal forcing and implications for larval transport. J Geophys Res C Oceans 105: 24141-24156

Brown CA, Holt SA, Jackson GA, Brooks DA, Holt GJ (2004) Simulating larval supply to estuarine nursery areas: How important are physical processes to the supply of larvae to the Aransas Pass Inlet? Fish Oceanogr 13:181-196

Carruthers T, Dennison W, Wazniak C, Hall M (2005) Coastal bays ecosystem health index: bringing it all together. In: Wazniak CE, Hall M (eds) Maryland's coastal bays: ecosystem health assessment 2004. DNR-12-1202-0009. Maryland Department of Natural Resources, Tidewater Ecosystem Assessment, Annapolis, MD, p 9.2-9.7

Casey JD, Doctor S (2005) Status of finfish populations in the Maryland coastal bays. In: Wazniak CE, Hall M (eds) Maryland's coastal bays: ecosystem health assessment 2004. DNR-12-1202-0009. Maryland Department of Natural Resources, Tidewater Ecosystem Assessment, Annapolis, MD, p 8.34-8.42

Casey JD, Wesche A (2001) Investigation of Maryland Atlantic Ocean and coastal bay finfish stocks. Federal Aid Project F-50R. Maryland Department of Natural Resources Fisheries Service, Annapolis, MD

Cushing DH (1990) Plankton production and year-class strength in fish populations: an update of the match/mismatch hypothesis. Adv Mar Biol 26:250-293

Fahay MP (1983) Guide to the early stages of marine fishes occurring in the western North Atlantic Ocean, Cape Hatteras, to the southern Scotian Shelf, Vol 4. Northwest Atlantic Fisheries Organization, Dartmouth, Canada

Hare JA, Able KW (2007) Mechanistic links between climate and fisheries along the east coast of the United States: explaining population outbursts of Atlantic croaker (Micropogonias undulatus). Fish Oceanogr 16:31-45

Hettler WF, Hare J (1998) Abundance and size of larval fishes outside the entrance to Beaufort Inlet, North Carolina. Estuaries 21:476-499

Hettler WF, Peters DS, Colby DR, Laban EH (1997) Daily variability in abundance of larval fishes inside Beaufort Inlet. Fish Bull (Wash DC) 95:477-493

Hilborn R (1997) Comment: recruitment paradigms for fish stocks. Can J Fish Aquat Sci 54:984-985

Jones PW, Martin FD, Hardy JD Jr (1978) Development of fishes of the Mid-Atlantic Bight. US Department of the Interior, US Fish and Wildlife Service, Biological Services Program, Washington, DC

Kudela RM, Chavez FP (2000) Modeling the impact of the 1992 El Niño on new production in Monterey Bay, California. Deep-Sea Res II 47:1055-1076

Love JW, May EB (2007) Species responses to environmental gradients in the coastal bays of Maryland. Northeast Nat 14:251-268

Love JW, Johnson AK, May EB (2006) Spatial and temporal differences of Atlantic menhaden (Brevoortia tyrannus) recruitment across major drainages (1966-2004) of the Chesapeake Bay watershed. Estuar Coast 29:794-801

McCune B, Grace JB (2002) Analysis of ecological communities. MjM Software Design, Gleneden Beach, OR

Murdy EO, Birdsong RS, Musick JA (1997) Fishes of the Chesapeake Bay. Smithsonian Institution Press, Washington, DC

Powles PM, Warlen SM (2002) Recruitment season, size, and age of young American eels entering an estuary near Beaufort, North Carolina-Anguilla rostrata. Fish Bull (Wash DC) 100:299-306

Quinlan JA, Blanton BO, Miller TJ, Werner FE (1999) From spawning grounds to the estuary: using linked individual-based and hydrodynamic models to interpret pat- terns and processes in the oceanic phase of Atlantic menhaden Brevoortia tyrannus life history. Fish Oceanogr 8: 124-133

> Rakocinski CF, Lyczkowski-Schultz J, Richardson SL (1996) Ichthyoplankton assemblage structure in Mississippi Sound as revealed by canonical correspondence analysis. Estuar Coast Shelf Sci 43:237-257

Ricker WE (1975) Computation and interpretation of biological statistics of fish populations. Bull Fish Res Board Can 191:1-382

> Rogers SG, Targett TE, VanSant SB (1984) Fish-nursery use in Georgia salt-marsh estuaries: the influence of springtime freshwater conditions. Trans Am Fish Soc 113:595-606

Sánchez-Velasco L, Avalos-García C, Rentería-Cano M, Shirasago B (2004) Fish larvae abundance and distribution in the central Gulf of California during strong environmental changes (1997-1998 El Niño and 1998-1999 La Niña). Deep-Sea Res II 51:711-722

Schaffler JJ, Reiss CS, Jones CM (2009) Patterns of larval Atlantic croaker ingress into Chesapeake Bay. Mar Ecol Prog Ser (in press)

Schwartz FJ (1964) Fishes of Isle of Wight and Assawoman Bays near Ocean City, Maryland. Chesap Sci 5:172-193

Searcy SP, Eggleston DB, Hare JA (2007) Environmental influences on the relationship between juvenile and larval growth of Atlantic croaker Micropogonias undulatus. Mar Ecol Prog Ser 349:81-88

Sinclair AF, Crawford WR (2005) Incorporating an environmental stock-recruitment relationship in the assessment of Pacific cod (Gadus macrocephalus). Fish Oceanogr 14:138-150

> Sorensen PW (1986) Origins of the freshwater attractant(s) of migrating elvers of the American eel, Anguilla rostrata. Environ Biol Fishes 17:185-200

Sullivan MC, Able KW, Hare JA, Walsh HJ (2006) Anguilla rostrata glass eel ingress into two, U.S. east coast estuaries: patterns, processes and implications for adult abundance. J Fish Biol 69:1081-1101

Taylor JC, Mitchell WA, Buckel JA, Walsh HJ and others (2009) Relationships between larval and juvenile abundance of winter-spawned fishes in North Carolina, USA. Mar Coast Fish Dyn Manag Ecosystem Sci 1:1-20

ter Braak CJF (1986) Canonical correspondence analysis: a new eigenvector technique for multivariate direct gradient analysis. Ecology 67:1167-1179

Tzeng WN (1985) Immigration, timing, and activity rhythms of the eel, Anguilla japonica, elvers in the estuary of northern Taiwan, with emphasis on environmental influences. Bull Jap Soc Fish Ocean 47-48:11-28

Warlen S, Able KW, Laban E (2002) Recruitment of larval Atlantic menhaden (Brevoortia tyrannus) to North Carolina and New Jersey estuaries: evidence for larval transport northward along the east coast of the United States. Fish Bull (Wash DC) 100:609-623

Wazniak C, Wells D, Hall M (2005) The Maryland coastal bays ecosystem. In: Wazniak CE, Hall M (eds) Maryland's coastal bays: ecosystem health assessment 2004. DNR-12-12020009, Maryland Department of Natural Resources, Tidewater Ecosystem Assessment, Annapolis, MD, p 9.2-9.7

Weinstein MP, Weiss SJ, Hodson RG, Gerry LR (1980) Retention of three taxa of postlarval fishes in an intensively flushed tidal estuary, Cape Fear River, North Carolina. Fish Bull (Wash DC) 78:419-436

Whitney FA, Welch DW (2002) Impact of the 1997-1998 El Niño and 1999 La Niña on nutrient supply in the Gulf of Alaska. Prog Oceanogr 54:405-421

Witting DA, Able KW, Fahay MP (1999) Larval fishes of a Middle Atlantic Bight estuary: assemblage structure and temporal stability. Can J Fish Aquat Sci 56:222-230 